\title{
INFANCIA, ADOLESCENCIA Y JUVENTUD EXTRANJERAS QUE MIGRAN DE FORMA AUTÓNOMA. ENTRE LA AGENCIA, LAS MOVILIDADES Y LAS FRONTERAS
}

\author{
MERCEDES G. JIMÉNEZ" \\ Dra. Antropología, Universidad Complutense de Madrid \\ mercedesg.jimenez@gmail.com \\ MARÍA AUXILIADORA TRUJILLO \\ Trabajadora social, SEPISE, Universidad de Granada \\ marutru@hotmail.com
}

RESUMEN: Este artículo reflexiona desde una mirada performativa sobre la presencia de niños, niñas, adolescentes y jóvenes menores de 18 años extranjeros, construidos jurídicamente como menores extranjeros no acompañados, dentro y fuera de los sistemas de protección en el Estado español y las interacciones que su presencia ha generado en los últimos 20 años. El texto tiene como objetivo la reflexión teórica desde el concepto de agencia sobre los significados de estas movilidades infantiles y adolescentes en un contexto transnacional. En una primera parte describiremos las implicaciones de una mirada agentiva poniendo especial interés en la cuestión de la migración autónoma y sosteniendo la importancia de generar otras narrativas y desbancar denominaciones raptadas en el nacionalismo epistemológico y metodológico como el uso intensivo de la categoría jurídica de "menores extranjero no acompañados". En la segunda parte, describiremos las performatividades de la presencia de estos menores en nuestras sociedades y territorios en estos últimos 20 años y las interacciones y tramas que sus subjetividades han reformulado y construido. Nos detendremos en tres aspectos, por un lado cómo la presencia de personas menores de edad marroquíes está contribuyendo a que los diferentes Sistemas de Protección de la Infancia comiencen a reflexionar en torno a la diversidad cultural y su gestión. Por otro lado, cómo se ha articulado un movimiento de defensa de derechos de los chicos y chicas extranjeras con importantes logros jurídicos que han beneficiado a la infancia y adolescencia en su conjunto. Finalmente, cómo nuevas formas de intervención social, como la mediación social transnacional, están poniéndose en marcha para acompañar la movilidad de estos niños, niñas, adolescentes y jóvenes y repensar la territorialidad de los sistemas de protección, que se revela como insuficiente. 
PALABRAS CLAVE: fronteras; niñez; adolescencia; juventud; migración autónoma; agencia; derechos; mediación social transnacional

ABSTRACT: From a performative perspective, this article reflects on the presence of foreign children, teenagers and adolescents under 18 years of age who are categorized legally both within and outside Spanish protection systems as unaccompanied foreign minors and analyses the interactions their presence has generated over the last 20 years. The aim is to conduct a theoretical reflection - based on the concept of agency - of the significance of these child and adolescent migrations in a transnational context. First we describe the implications of an agential view, where we place special emphasis on the issue of autonomous migration and support the importance both of generating other narratives and dismantling the terminology that is extracted from epistemological and methodological nationalism, such as the widespread use of the 'unaccompanied foreign minor' legal category. We then describe the performativities of the presence of these minors in our regions and societies over the last 20 years as well as the interactions and patterns that their subjectivities have reformulated and constructed. We will focus on three aspects: how the presence of Moroccan minors is helping the various child protection systems to reflect on cultural diversity and learn how to manage it; how a movement to defend the rights of foreign minors has been created and how this movement has made important legal progress that has benefitted children and adolescents in general; and how new forms of social intervention, such as transnational social mediation, are being implemented in order to accompany these children, teenagers and adolescents in their mobility and to rethink the territoriality of protection systems, which are deemed to be insufficient.

KEYWORDS: borders; childhood; adolescence; youth; autonomous migration; agency; rights; transnational social mediation

\footnotetext{
"Este artículo ha sido posible gracias a un contrato posdoctoral de la Universidad Complutense de Madrid. Mercedes Jiménez es doctora en Antropología Social, investigadora posdoctoral en la UCM e investigadora del Centro ACRES (Centro Transfronterizo de Acción Cultural e Investigación Social) en Tánger (Marruecos), donde vive desde hace veinte años. Ha llevado a cabo varias investigaciones sobre los perfiles, contextos, movilidades de chicos y chicas marroquíes en estos procesos de movilidad, incluida su tesis doctoral.

** María Auxiliadora Trujillo es trabajadora social y lleva más de quince años dedicada a la protección de la infancia y la adolescencia en la Administración pública. Es miembro del SEPISE (Universidad de Granada) y ha realizado diferentes investigaciones, específicamente sobre las trayectorias de niñas y adolescentes. Este texto es una versión mejorada, ampliada y actualizada de otro artículo publicado por el Instituto de Estudios Hispano-Lusos (IEHL) de la Universidad Mohamed V de Rabat (Marruecos) sobre la diáspora marroquí y sus aportes a los países de recepción, titulado «Las movilidades de adolescentes marroquíes y su aportación al trabajo social». Ambas autoras buscan — partiendo de una amplia trayectoria de trabajo directo con estos y de reflexiones compartidas con profesionales de diferentes disciplinas - visibilizar sus múltiples aportes en un contexto transnacional de movilidades e intercambios.
} 
¿Y tú por qué puedes moverte y yo no? Todo depende del color de tu pasaporte, ¿no?

Sufian, 13 años, Tánger.

\section{Introducción ${ }^{1}$}

Este artículo reflexiona desde una mirada performativa sobre la presencia de niños, niñas, adolescentes y jóvenes menores de 18 años extranjeros, construidos jurídicamente como menores extranjeros no acompañados $^{2}$, dentro y fuera de los sistemas de protección en el Estado español y las interacciones que su presencia ha generado en los últimos veinte años. En el contexto contemporáneo, la migración protagonizada por personas menores de edad extranjeras que dejan a las «familias atrás» llama la atención de la academia, las políticas de protección de la infancia y de extranjería, los organismos internacionales y las organizaciones de defensa de derechos de las personas migrantes y de protección de la infancia. Por un lado, son personas menores de edad a proteger — según el derecho internacional-, y, por otro lado, personas extranjeras a controlar - según las legislaciones de extranjería-. Desde mediados del siglo xx se generaliza un consenso sobre la construcción de la infancia como sujeto de derecho y merecedor de una forma específica de protección recogida en el derecho internacional. Este consenso ha desarrollado formas de gobierno, legislaciones e instituciones internacionales centradas en la protección. Sin embargo, cuando el sujeto a proteger es un «menor de edad extranjero» que ha accedido al territorio de forma irregular se producen diferentes formas de maltrato institucional. En la génesis de

1 Este artículo ha sido financiado en el marco de la investigación posdoctoral «Relaciones transfronterizas, movilidades y políticas de la compasión en la frontera sur de Europa: Una reflexión sobre las movilidades adolescentes», llevada a cabo en calidad de investigadora posdoctoral del Departamento Sociología Aplicada de la Universidad Complutense de Madrid (contrato postdoctoral UCM - BOUC, 24.07. 2017).

2 Resolución de 26 de junio de 1997 (97/C221/03): «Menores de 18 años nacionales de países terceros que lleguen al territorio de los Estados miembros sin ir acompañados de un adulto responsable de los mismos, ya sea legalmente o con arreglo de los usos o costumbres, en tanto en cuanto no estén efectivamente bajo el cuidado de un adulto responsable de ellos. La presente Resolución podrá aplicarse también a los menores nacionales de terceros países que, después de haber entrado en el territorio de los Estados miembros, sean dejados solos. Las personas contempladas en los dos párrafos anteriores se denominarán en lo sucesivo "menores no acompañados"». 
este maltrato está la preeminencia del control fronterizo en las políticas migratorias mundiales y el hecho de que estos chicos y chicas migran y se mueven poniendo en crisis estos sistemas de control migratorio. La titularidad de sus derechos está constantemente puesta en duda por su doble condición de menores y extranjeros. Los sistemas de protección de la infancia y la adolescencia están raptados por la incapacidad de hacer prevalecer el mandato de la protección en esta doble condición. Condición que les construye desde los medios de comunicación convencionales y los discursos políticos normativos desde una visibilidad «alienante» (Bargach, 2006) y como un sujeto social criminalizado (Empez, 2015). La imagen de niños temblorosos que desembarcan en las costas europeas tras travesías peligrosísimas perpetúa una visión mediatizada y racista sobre la complejidad de sus motivaciones y raptada en la «industria de la compasión». Esta visión «alienante» rapta también parte de la obra etnográfica reciente sobre estos chicos y chicas que se empeña es describirlos, contarlos y analizar sus comportamientos como forma de contención y prevención de esta migración.

Este artículo tiene como objetivo la reflexión teórica desde el concepto de agencia sobre los significados de estas movilidades infantiles y adolescentes en un contexto transnacional. En una primera parte del artículo describiremos las implicaciones de una mirada agentiva poniendo especial interés en la cuestión de la migración autónoma y sosteniendo la importancia de generar otras narrativas y desbancar denominaciones raptadas en el nacionalismo epistemológico y metodológico como el uso intensivo de la categoría jurídica de «menores extranjeros no acompañados». En la segunda parte del texto, describiremos las performatividades de la presencia de estos menores en nuestras sociedades y territorios en estos últimos veinte años y las interacciones y tramas que sus subjetividades han reformulado y construido. 


\section{Desde el prisma de la agencia: la migración autónoma}

Los autores que reflexionan sobre la capacidad de agencia y los menores en la migración son escasos (Honwana y De Boeck, 2005; Whitehead y Hashim, 2005). Tradicionalmente, la migración de los niños y niñas es analizada en la órbita familiar y atrapada en el binomio de las perspectivas proteccionistas y las perspectivas criminalizadoras. Analizar la capacidad de agencia de los niños, niñas y adolescentes en la migración tiene que ver con profundizar en los significados y potencialidades en el entramado transnacional de las migraciones. Con frecuencia la lente académica centra la atención en los procesos migratorios de los adultos y los niños y niñas quedan eclipsados por estos. Progresivamente, diferentes autores han comenzado a destacar el papel central que los niños y niñas desempeñan en los procesos migratorios familiares. Como subrayan Levitt y Glick-Schiller (2008: 206): «Los niños constituyen el eje central de la migración familiar y con frecuencia son un argumento crucial por el cual la familia se traslada de un lugar a otro y conserva lazos transnacionales».

Le Gall (2005:34) destaca el hecho de que los niños participan de forma activa en los procesos migratorios de sus familias, los describe como puntos centrales de apoyo en las estrategias transnacionales que las familias llevan a cabo. Otros autores (Orellana et al., 2001; Olwing, 1999) también subrayan que los menores son vistos como actores que desempeñan un papel activo en los procesos migratorios vinculados a sus familias.

Nuestra mirada pretende ser aún más intrépida. Para nosotras es posible ir más allá y pensar en la migración autónoma de estos niños, niñas y adolescentes desde una mirada agentiva y de forma separada de la familia, aunque en relación e interacción con ella. Las personas menores de edad no son comprendidas entonces únicamente dentro de las lógicas de dependencia del grupo doméstico, sino que la edad — como también el género- descifra las relaciones de poder dentro de la familia y permite la subjetivación de sus miembros y conforma la base de una autonomía. Socioantropológicamente existe en estas movilidades adolescentes (Ribas-Mateos et al., 2014) una dimensión que permite desligar los intereses del grupo doméstico de los intereses de estos grupos etarios y definir las relaciones de poder e interacciones. De este modo, subrayamos cómo en 
los procesos migratorios los chicos y las chicas son los protagonistas y toman decisiones por sí mismos, asumen riesgos y establecen estrategias. Estas decisiones autónomas están condicionadas por sus circunstancias, recursos y objetivos propios y no solamente por los de sus familias, que pueden tener más o menos peso (desde una consonancia y un pacto familiar hasta una ruptura total con la familia).

Cuando hablamos de las circunstancias que les atañen nos referimos al contexto específico que construye su subjetividad (su historia escolar, una primera experiencia laboral, su orientación sexual, la relación con la familia, la relación con los amigos y amigas, el deseo de promocionar, las diferentes violencias estructurales o vitales y su historia de vida). Al hablar de los recursos propios e intransferibles destacamos sus redes de iguales, su formación, capacidad de resiliencia o su capital social. Finalmente, al hablar de objetivos distinguibles nos referimos a las metas o finalidades de los propios sujetos que difieren de las decisiones familiares aunque también es posible que puedan guardar cierta consonancia. Estos tres elementos son las claves fundamentales en la construcción de esta forma de movilidad autónoma (Jiménez-Álvarez, 2011; 2015).

Esta mirada desde la agencia pasa por comprender que los menores de edad que migran fuera del grupo doméstico están inaugurando una nueva forma de moverse. Son constructores activos de estrategias de supervivencia efectivas (Suárez, 2006). Su movilidad pone de manifiesto una trasgresión social: por un lado, cuestiona las relaciones de género y generación dentro de la familia, y, por otro, pone en crisis la territorialidad de los sistemas de protección en Europa, cuya presencia supone un reto para los mandatos jurídicos de protección de la infancia y de la adolescencia del derecho internacional.

Finalmente, desde la capacidad de agencia también reformulamos la mirada sobre la familia a través del prisma de su movilidad autónoma. Es interesante analizar la situación de las familias a partir de las decisiones tomadas por los chicos y chicas menores de edad, en vez de, como tradicionalmente se piensa, analizar a los «menores en la migración» en la órbita de las decisiones familiares. La bibliografía al uso señala las categorías de los menores en la migración como los menores «dejados atrás» 
cuando emigra alguno de los progenitores, los menores que migran con alguno de sus progenitores o los que migran de forma no acompañada. Sería necesario ampliar el campo epistemológico y analizar estos procesos subrayando el papel central que pueden llegar a tener los hijos e hijas en estos procesos familiares. En este sentido, tendríamos que incorporar las situaciones en las que son los chicos y las chicas los que migran y las familias son las «dejadas atrás». Esta situación es posible en dos circunstancias. Por un lado, cuando los que encabezan la migración, por ser los autores estratégicos de un proyecto familiar, son los menores de edad (Orellana et alii, 2001), como en el caso de los menores surcoreanos que emigran a Nueva Zelanda, EE. UU. o Canadá. Y la otra situación posible acontece cuando el proyecto migratorio es fruto de una «decisión autónoma» del chico o de la chica. Es decir, en el caso de los menores surcoreanos existe casi siempre una estrategia transnacional familiar, siendo los hijos los que «inauguran» un proceso migratorio que los padres concluirán años después. En el caso de los menores que migran de forma autónoma, y me refiero específicamente a los menores de edad marroquíes, los padres no serán reagrupados al país donde se encuentra el chico mientras estos permanezcan en su condición de menores de edad. Y podemos afirmar que tampoco se aprecia en el tiempo que sean más numerosos los procesos de reagrupación familiar de adultos que fueron menores extutelados, ya que esta condición no supone ninguna ventaja en el proceso de reagrupación familiar.

Hablar de migración autónoma también tiene como objetivo desbancar denominaciones raptadas en el nacionalismo epistemológico y metodológico, como el uso de la categoría jurídica de «menores extranjeros no acompañados», que sesga la complejidad social de esta movilidad. Siendo el concepto jurídico apropiado para describir la titularidad de derechos y deberes, al utilizarse de forma extensiva para describir las movilidades de los niños, niñas, adolescentes y jóvenes menores de edad que migran de forma autónoma, se impone una construcción etnocéntrica de la infancia, la adolescencia y su protección. 


\section{Performatividad de la presencia de niños, niñas, adolescentes y jóvenes extranjeros que han migrado de forma autónoma}

Explorar la capacidad de agencia también supone ampliar el ángulo de análisis de las construcciones epistemológicas sobre los chicos y chicas que migran de forma autónoma y reconocer la performatividad de su presencia en las sociedades receptoras. A continuación queremos realizar una reflexión sobre cómo en estos últimos veinte años la presencia de niños, niñas, adolescentes y jóvenes menores de edad marroquíes ha significado una oportunidad para reformular la forma de gestionar la diversidad cultural e intervenir desde el trabajo en red, la interdisciplinariedad y con una perspectiva más allá del territorio. Nos detendremos en tres aspectos. Por un lado, cómo la presencia de personas menores de edad marroquíes está contribuyendo a que los diferentes sistemas de protección de la infancia comiencen a reflexionar en torno a la diversidad cultural y su gestión. Por otro lado, cómo se ha articulado un movimiento de defensa de derechos de los chicos y chicas extranjeros con importantes logros jurídicos que han beneficiado a la infancia y adolescencia en su conjunto. Finalmente, cómo nuevas formas de intervención social, como la mediación social transnacional, están poniéndose en marcha para acompañar la movilidad de estos niños, niñas, adolescentes y jóvenes y repensar la territorialidad de los sistemas de protección, que se revela como insuficiente. La movilidad infantojuvenil de origen marroquí en este mundo globalizado es una ventana de oportunidad para pensar el trabajo social transnacional.

a) Una oportunidad para pensar la gestión de la diversidad en los sistemas públicos de protección de menores del Estado español

El sistema de protección a la infancia se desarrolla en el Estado español tardíamente, en los ochenta y noventa se establecen las normas básicas que lo regula. Es un sistema pensado en el contexto de la transición democrática que se crea al albur del desarrollo del sistema de bienestar social que se pretende construir en esos momentos. Reflejo de los deseos 
y anhelos de democracia de la época, las leyes y normas que se van a desarrollar dirigidas a la infancia son muy garantistas con los derechos de las niñas y los niños, focalizando el interés superior del menor como el eje central de cualquier actuación en los diferentes ámbitos en los que las niñas y los niños se desenvuelven. Este interés superior también se convierte en guía de las políticas que se han de dirigir a los colectivos que conforman la infancia y la adolescencia.

La llegada de chicos y chicas extranjeros al territorio español sin estar acompañados por referentes adultos responsables de su atención y protección se produce a partir de la década de los noventa del siglo xx y se configura en un principio como un fenómeno marroquí, dado que prácticamente la totalidad de los chicos provenían de Marruecos (Trujillo, 2006). Estos menores van a ser atendidos con los medios y recursos del sistema de protección, sin embargo, la aceptación y la acogida de estos menores, al menos inicialmente, van a estar condicionadas por una reacción de rechazo. Los menores marroquíes son considerados un problema, y además un problema ajeno, y, por tanto, no se consideran menores a acoger, evidenciándose una gran contradicción con los principios que inspiraron ese sistema llamado a proteger a las niñas y los niños. Los discursos de los responsables políticos y dominantes en los medios de comunicación son una voz unánime que llama a la devolución, al retorno, a la expulsión, en definitiva, de estos chicos a Marruecos, su país de procedencia.

El hecho de migrar de forma autónoma, sin referentes familiares que les protejan, que les acompañen en sus proyectos vitales, que les provean de medios para su alimentación y cuidados físicos, que los acompañen afectivamente y que les pongan límites a sus comportamientos, es característico y les conforma como un grupo en situación de vulnerabilidad y de grave riesgo de desprotección y de exclusión social, y, en consecuencia, necesitado del amparo institucional.

A finales de los noventa, la limitada experiencia en los diferentes ámbitos de la sociedad en la atención a la diversidad, en general, y, en concreto, a la inmigración, evidenciaba vacíos importantes en la gestión de los planes, programas, recursos, protocolos de intervención de los colec- 
tivos de migrantes en general y, específicamente, de la atención, intervención y protección de los niños marroquíes que estaban llegando.

En la intervención con estos chicos y chicas se ha venido produciendo una tensión, no exenta de contradicciones, entre discurso y práctica. Un pulso constante entre una realidad que se impone - la evidente presencia de menores que optan por la movilidad-y la inadecuación de las respuestas institucionales del sistema de protección todavía en los momentos actuales siguen ancladas en un enfoque de la protección que gira en torno de las situaciones de maltrato familiar.

Desde este punto de partida, la presencia de estos chicos marroquíes deviene una gran oportunidad para pensar en la mejora de la atención a la infancia y en la adecuación de las formas de protección más acordes con las necesidades actuales de la infancia en el siglo xxi. Se produce, en consecuencia, una oportunidad para pensar en la gestión de la diversidad cultural, tomar mayor conciencia de la importancia de la supervisión de equipos y de la importancia de la formación.

Los actores sociales de los ámbitos institucionales y de la sociedad en su conjunto han tenido que ir implementando actuaciones para hacer viable la convivencia de estos chicos y chicas en los contextos en los que necesitan desenvolverse para su adecuado desarrollo, social, educacional, cultural y de ocio, y surgen prácticas diferentes buscando estrategias facilitadoras de la intervención.

Los centros de protección son, por excelencia, el ámbito de convivencia de los menores. En estos centros los chicos y chicas desarrollan su vida cotidiana apoyados por los equipos de profesionales que buscan facilitar la inclusión en la sociedad receptora, cuestiones no contempladas con anterioridad a la llegada de este colectivo. Nuevos perfiles profesionales surgen como instrumentos para hacer factible la cobertura de las necesidades de los menores y el ejercicio de sus derechos.

Comienzan a plantearse aspectos relacionados con la interculturalidad. El idioma, las costumbres y las concepciones culturales y religiosas están presentes e impulsan a plantear a las instituciones responsables y a la Administración pública una gestión de estos aspectos que pasa por la inclusión en las plantillas de profesionales de la mediación intercultu- 
ral o la implementación de cursos de formación en torno a la diversidad cultural. Surgen numerosos programas en torno a la relación intercultural en distintos espacios sociales: en los centros educativos en los que estos chicos son escolarizados y en diferentes ONG que ofrecen alternativas interculturales de ocio, de formación o acompañamiento. Muchos profesionales aprenden la lengua árabe, más concretamente, la dariya o idioma marroquí, y programan visitas a Marruecos o participan en acciones formativas organizadas en ese país, profundizando así en los conocimientos directamente relacionados no solo con las chicas y los chicos marroquíes y sus trayectorias, sino también con los contextos rurales y urbanos de los que proceden. En definitiva, se produce un interés por los contextos de procedencia de los menores, se materializan mayores intercambios en los que participan familiares, profesionales y otros agentes sociales y se realiza un ejercicio de transnacionalidad con repercusiones, directas e indirectas, en una mayor comprensión de estas personas y sus trayectorias de vida, en un mejor entendimiento y aproximación de estas sociedades.

La llegada de estos chicos y chicas ha tenido para muchos profesionales de diferentes ámbitos un efecto de oportunidad para el ejercicio profesional, un estímulo en su proceso de formación profesional y personal, una repercusión directa en producciones científicas, el desarrollo de investigaciones y publicaciones o en formas de activismo en la defensa de derechos de estos niños y niñas y en cuestiones que permean otras concepciones sobre la infancia, sobre sus necesidades, y sobre las maneras de atender y abordar los problemas de los niños y las niñas que emigran basadas en una perspectiva de derechos.

Nos gustaría detenernos en la experiencia formativa llevada a cabo en Tánger durante cinco años (2009, 2010, 2011, 2012 y 2014) en la Escuela de Trabajo Social (INAS) por parte de la asociación Alkhaima. Unos doscientos profesionales de la intervención social (psicología, trabajo social, educación social y pedagogía) de diferentes países tuvieron la posibilidad de formarse y contar con un espacio privilegiado de reflexión. El hecho de llevar a cabo esta formación en Marruecos invirtió el orden convencional de la construcción del conocimiento en contextos neoliberales, donde el 
norte convencional produce un conocimiento que el resto de academias «replican». En este sentido, la construcción del conocimiento se realizaba desde la periferia y los profesionales del «norte» acudían a formarse al país de origen de sus «usuarios». Esto contribuyó a reformular la construcción etnocéntrica sobre los saberes en la intervención social y mejoró la compresión de los procesos sociales. Estos intercambios ayudaron a valorar la importancia del trabajo en red (entre diferentes ciudades, provincias, CC. AA. y países) y el valor del trabajo interdisciplinar (al contar con diferentes perfiles profesionales). La motivación común de muchos de los participantes era poder reformular sus prácticas cotidianas dentro de los recursos de los sistemas de protección de la infancia para armonizarlos con las trayectorias vitales de los nuevos «usuarios» llegados al sistema.

Aún las tareas pendientes son muchas. Es necesario visibilizar y afrontar los problemas, situaciones, necesidades y derechos de la infancia actual, que trasciende lo territorial. En relación con los sistemas de protección territoriales diremos, además, que debemos afrontar el reto de un verdadero cambio en la mirada y atención de las niñas y los niños, adolescentes y jóvenes necesitados de protección, y que en su estructura institucional (políticas sociales, normas legales, medidas, líneas de actuación, procedimientos técnicos y administrativos, recursos, prácticas de atención, etc.) no debe seguir primando una concepción de la atención a la infancia centrada en aquellas situaciones de los niños y niñas que sufren malos tratos en el ámbito familiar en cualquiera de sus modalidades, sino una apuesta real por concepciones ligadas y centradas en el respeto y garantía de los derechos que se les reconocen, en la atención a sus necesidades, en su interés superior y en las que se tengan presentes las formas de movilidad que ejercen estos jóvenes y a las que hemos aludido en este capítulo. 


\section{b) Una oportunidad para construir nuevas formas de defensa de los derechos de la infancia}

La vulneración de los derechos de los menores extranjeros en el Estado español ha movilizado una serie de acciones políticas en favor de la defensa de sus derechos, que ha tenido un impacto en la propia forma de pensar la protección de la infancia y adolescencia autóctonas. Los menores extranjeros marroquíes que llegan sin un referente adulto a los sistemas de protección sufren diferentes formas de maltrato institucional, al tratarse de menores no nacionales para los que no se pensaron los sistemas de protección, principalmente orientados a menores nacionales. De forma intermitente, la titularidad de los derechos de los menores migrantes está constantemente puesta en duda. El Defensor del Pueblo ha llamado la atención sobre la ambivalencia entre una regulación protectora y una práctica vulneradora (Defensor del Pueblo, informes anuales de 2001 a 2019). Los derechos vulnerados de estas personas menores de edad extranjeras que han llegado de forma «no acompañada» tienen que ver con: la imposibilidad de ejercer el derecho a una tutela judicial efectiva; el limitado o inexistente ejercicio del derecho a ser oído; la lentitud, demora excesiva o la no tramitación en la obtención de la autorización de residencia y permiso de trabajo o la imposibilidad de obtenerlo; las pruebas de determinación de la edad aplicadas de forma invasiva y de forma abusiva; la falta de diligencia en la atención integral a estos menores a nivel educativo y sanitario; la descoordinación entre Administraciones e incluso el maltrato institucional y el modo en que se llevaron a cabo las repatriaciones y/o las reagrupaciones familiares.

El escenario por antonomasia donde se consumó el maltrato institucional fue el modo en que desde el año 2004 a 2007 se llevaron a cabo las reagrupaciones familiares en Marruecos. Ante este maltrato institucional, la Fundación Raíces y el abogado Juan Ignacio de la Mata lideraron, con el apoyo de otras entidades, abogados, personas e instituciones en España y Marruecos (SOS RACISMO, Colectivo Al Jaima, CGAE, CEAR, Coordinadora de Barrios, etc.) una serie de acciones de defensa efectiva de derechos fundamentales de estos chicos y chicas que estaban siendo expulsados a Marruecos. Estas acciones permitieron que la Realpolitik en 
torno a las repatriaciones fuera cuestionada y fiscalizada por los tribunales, siendo el resultado un conjunto de sentencias que redefinieron la legislación de extranjería en aras de la protección de la infancia, en relación con cuestiones como la tutela judicial efectiva y el derecho a ser oído (Unicef y CGAE, 2009; Barbulescu y Grugel, 2016).

En febrero de 2003, un grupo de asociaciones denunció ante la Fiscalía de Menores de Madrid que siete niños habían sido repatriados a Marruecos sin garantías. Los menores contaban que la policía había llegado de noche a su centro, les había despertado y les había conducido al aeropuerto sin darles ninguna explicación ni tampoco avisar a su familia. Era la primera vez que un grupo de asociaciones se movilizaban para hacer saber estas prácticas a la Fiscalía. La mayor parte de estos menores fueron repatriados a Tánger. Desde principios de 2004, comenzó una política activa de repatriación de chicos menores de edad marroquíes. Las comunidades autónomas eran las que proponían las medidas de repatriación y las subdelegaciones del Gobierno las ejecutaban. Las que se ejecutaron fueron cuantitativamente pocas en relación con las propuestas, sin embargo, el modo en que estas se llevaron a cabo - mayoritariamente de forma contraria a la ley, contraviniendo el ordenamiento y vulnerando derechos fundamentales de las personas menores de edad tuteladas - mostraba el talante punitivo de estas medidas y el alejamiento de la búsqueda del interés superior del menor. Más que repatriaciones se estaban llevando a cabo expulsiones, pero sin dar a la persona extranjera la posibilidad de defenderse de tales actuaciones. A mediados de 2005, cuarenta organizaciones firmaron un manifiesto dirigido a la Delegación del Gobierno y al Instituto Madrileño del Menor y la Familia (IMMF) por vulnerar los derechos de los estos chicos extranjeros. Denunciaban las reagrupaciones sin garantías que se estaban produciendo. Señalaban que en estos procedimientos no se estaba tomando en consideración la opinión del menor y se vulneraba el derecho a ser oído; no se le notificaba previamente la resolución de reagrupación, vulnerando el derecho a interponer un recurso; no se garantizaba un análisis individualizado de cada caso, al no escucharse las recomendaciones y valoraciones de los equipos educativos e instituciones encargadas de su guarda; no se les 
reconocía el derecho a la asistencia letrada independiente en el proceso de reagrupación; no se garantizaba el retorno a su entorno familiar o al sistema de protección, y, en algunos casos, tras sacarlos de los pisos por la noche y montarlos en un avión, se les dejaba en ciudades alejadas de su lugar de origen en Marruecos, a veces en comisarías de policía, donde habían sido maltratados. Durante todo el año 2005 se intentó repatriar a 412 menores y solo se consiguió con 65 . El 5 abril de 2006, a las 5 de la mañana, un grupo de policías llegaron al centro donde dormía Bouabib, al que llamaban Boby, y le despertaron para llevárselo a Marruecos. A las 9 de la mañana, el letrado Juan Ignacio de la Mata interpuso una medida cautelarísima en los juzgados de lo Contencioso-Administrativo de la Comunidad de Madrid. Seis minutos antes de que el avión despegara, llegó un fax a la Comisaría del Aeropuerto de Barajas ordenando que el menor de edad bajara del avión. El menor no había sido escuchado, ni se le había notificado la resolución de repatriación. Unos meses después el juez del Juzgado n. ${ }^{\circ} 14$ de lo Contencioso-Administrativo estimó parcialmente el recurso y señaló que la resolución del delegado del Gobierno donde se acordaba la repatriación del menor infringía el ordenamiento jurídico y la declaró nula. El chico no había sido oído en el procedimiento y nadie le notificó esta decisión. El menor de edad tenía derecho a estar en desacuerdo con esta decisión de la Administración, aunque esta fuera su tutora y el niño estuviera a su cargo.

Comenzó en este momento todo un proceso de defensa efectiva de los menores extranjeros que estaban siendo repatriados sin garantías. Hasta treinta reagrupaciones fueron recurridas ante los tribunales de distintas comunidades autónomas, resultando numerosas sentencias que establecían que por distintas vulneraciones de derechos estas repatriaciones se habían realizado sin garantías. Especialmente importantes fueron las sentencias de la Sala Primera del Tribunal Constitucional 183/2008 y 184/2008. Se reconocía que estos chicos tenían derecho a una tutela judicial efectiva que los protegiese de una posible actuación arbitraria de la Administración. La vulneración de los derechos de los menores extranjeros en el Estado español movilizó una serie de acciones políticas en favor de la defensa de sus derechos que también repercutía en la forma de 
conceptualizar la protección de la infancia y la adolescencia en general y su capacidad de obrar. Es interesante subrayar que la forma de pensar la capacidad de obrar de los menores extranjeros tiene que ver con la posibilidad de interponer un recurso contencioso-administrativo para recurrir una decisión administrativa contraria a su interés superior. La capacidad de obrar (que podría ser entendida como una expresión de su capacidad agencia) es en este contexto la posibilidad de oponerse a la decisión de su tutor (en este caso la comunidad autónoma) y pedir el amparo en los tribunales por una actuación vulneradora de derechos fundamentales. Este reconocimiento, esta capacidad de agencia, pone en jaque el propio concepto jurídico de menor, atrapado entre una construcción de la infancia que la limita y otra más flexible que reconoce a los menores de edad una capacidad progresiva para ejercer sus derechos. La forma en que se ha defendido a los menores de edad extranjeros ha contribuido a reformular los estrictos límites legales de la propia definición jurídica de los menores de edad y ha promovido acciones jurídicas que reconocen esa capacidad progresiva para ejercer sus derechos.

\section{c) Una oportunidad para pensar el trabajo social desde la movilidad: la mediación social transnacional}

Los niños, niñas y adolescentes que participan hoy activamente en procesos globales de movilidad desafían las representaciones internalizadas sobre la infancia dependiente y muestran que las prácticas institucionales de la protección de la infancia necesitan incorporar esta movilidad. La comprensión de los procesos que protagonizan los chicos y chicas que migran de forma autónoma está raptada por la territorialidad del sistema de protección. Este rapto territorial de la percepción de la migración también está presente en la concepción de la propia protección que se ofrece. Por este motivo, es necesario desterritorializar la comprensión de la protección de la infancia cuando nos referimos a la migración de los menores de edad. En este sentido, es el transnacionalismo el inspirador de nuevas formas de intervención y militancia social. Pensamos el transnacionalismo como una «nueva forma de mirar los procesos migratorios» y como un modo de inspirar la creación o la reformulación de acciones 
ligadas a la defensa de los derechos de las personas migrantes y a la intervención social.

Bargach (2006) define al menor que migra como un ser social en posesión de redes sociales complejas. El menor de edad quedaría caracterizado por una doble pertenencia. Por un lado, la pertenencia al sistema social de procedencia, donde el menor de edad inició una socialización en el seno de un sistema familiar. El segundo aspecto se centra en el sistema social receptor donde el menor de edad está ubicado cumpliendo la tarea de completar su socialización-emancipación en busca de construir un proyecto de vida que le ha sido denegado en su país de procedencia. Nos encontramos, por tanto, ante unos chicos y chicas que se socializan en dos sistemas, el sistema social de procedencia y el sistema social del contexto de recepción. Los marcos normativos, predominantemente de control, que regulan los diferentes aspectos de la vida de las personas menores de edad extranjeras una vez se encuentran en este contexto, así como la aplicación práctica de los mismos, actúan como una gran barrera para la interconexión entre un sistema y otro. Los menores se visibilizan de forma fragmentada, sus contextos referenciales no se consideran cuando se planifican y se llevan a cabo las acciones inherentes a la protección y cuando son tenidos en cuenta se proyectan desde una mirada etnocéntrica y estereotipada. Nada más significativo de esta realidad que la denominación jurídica que reciben en los países receptores, menores extranjeros no acompañados, y que se utiliza de forma intensiva para nombrar la complejidad de esta realidad migratoria. Se parte de un nacionalismo epistemológico y metodológico y se fragmenta la forma de pensar la vida de estos chicos y chicas.

La práctica profesional necesita formas de intervenir para proteger y acompañar a los chicos y chicas extranjeros en sus procesos vitales que rompan con esa concepción territorializada de la protección y busquen una comprensión complejizada de sus proyectos de vida en pro de un adecuado desarrollo integral y de su inclusión social como ciudadanos y ciudadanas de pleno derecho.

Otra aportación en la búsqueda de la mejora de la intervención con el colectivo de menores extranjeros marroquíes que han migrado de forma 
autónoma es la implementación de un novedoso instrumento de trabajo social que permite considerar la movilidad en la concepción de la acción protectora, hablamos de la mediación social transnacional (Montesino y Jiménez, 2015). Su aporte cobra mayor valor en tanto que no solo mejora las prácticas profesionales dirigidas a la atención de los menores, sino que, además, es un concepto transferible a la intervención con otros sectores de la población migrante y no migrante.

La mediación social transnacional, como su propio nombre indica, consiste en mediar, en construir un contexto psicosocioeducativo transnacional entre la familia, el tejido asociativo, las instituciones públicas y los menores migrantes. La principal orientación de esta mediación social es acompañar el proceso migratorio sin criminalizarlo. Busca dar un marco de referencia a los menores de edad extranjeros y responsabilizar a la familia, instituciones públicas y asociaciones de su papel en la protección funcional de la infancia y la adolescencia extranjera. En la formulación de la mediación social transnacional, por un lado, se apuesta por una visión transnacional de la migración. Se aboga por una visión holística del proceso migratorio, por una intervención que incorpore el proceso de vida y que no segmente a la persona en función de la construcción política sobre ella. Y, por otro lado, se apuesta por una dimensión inclusiva de la intervención con chicos y chicas menores de edad extranjeros desde la perspectiva general de la protección de los derechos de todas las personas menores de edad. Comporta acciones simultaneadas en el contexto de procedencia y receptor dirigidas a producir cambios que favorezcan el desarrollo de las personas, que nos ayuden en la comprensión del proyecto de vida, que interaccionen los marcos de pertenencia en los que el menor de edad participa y que fortalezcan los vínculos afectivos entre los chicos y chicas, las familias y sus contextos.

La mediación social transnacional es un concepto teórico-práctico que está en construcción y surge en un contexto de trabajo en red entre varias entidades que tienen por objetivo la defensa de los derechos de los menores extranjeros yendo más allá de las fronteras, del intercambio de las experiencias de diferentes profesionales de los ámbitos académico, profesional y social, y del ejercicio de unas prácticas concretas que se 
vienen impulsando desde la asociación marroquí Alkhaima, cuya sede se encuentra en Tánger (Marruecos).

En la formulación de la mediación social transnacional se apuesta por una visión de la migración compleja y no territorializada. Ha sido la presencia en los sistemas de protección de la infancia en Europa lo que ha concedido una visibilidad a los menores migrantes y determinado el tipo intervención con ellos (control, protección, repatriación). Las instituciones que trabajan con ellos (Administración pública, entidades de tutela, asociaciones, universidades) se han centrado en la parte del proceso migratorio que «se desarrolla» espacialmente en el territorio en el que están presentes estas instituciones. Partiendo de una reflexión desde el sur - geográfico y político- desde la mediación social transnacional se aboga por una visión holística del proceso migratorio, por una intervención psicosocioeducativa que incorpore a la familia (y no exclusivamente para fundamentar una repatriación al país de procedencia) y que incluya el proceso de vida y no segmente a la persona en función de la construcción política sobre ella. En este sentido, la perspectiva transnacional es un soporte teórico y metodológico para fundamentar la intervención.

Se busca una dimensión inclusiva de la intervención desde la perspectiva general de la protección de los derechos de todos los menores de edad, evitando así el efecto perverso de convertir la intervención con menores extranjeros en una forma de promoción de la migración en sí. Se ponen en cuestión las actuaciones que se están llevando a cabo en relación con la «prevención de la migración de menores de edad», la mayoría de las veces aplicadas como formas de «disuasión de la migración» (especialmente en Marruecos y Senegal), y se apuesta por una labor de comprensión y acompañamiento de los procesos migratorios desde una perspectiva de defensa de derechos. En la mediación social transnacional son claves tres elementos: el trabajo en red y la creación de redes transnacionales de protección; el trabajo con los menores y sus familias de forma sincrónica, y la formación de profesionales desde una dimensión transnacional.

A modo de conclusión, pensamos que no corren buenos tiempos para estos adolescentes que se mueven solos. El celo del control fronterizo parece ser mucho más fuerte que las leyes de protección de la infancia. Pero 
es un deber construir discursos contrahegemónicos que rompan la voz única del control de las fronteras. La llegada de estos chicos y chicas a nuestras sociedades ha supuesto una oportunidad para madurar y para poner a prueba nuestras leyes de protección de la infancia. Es un deber para nosotras, como profesionales y académicas, reflexionar sobre la riqueza del encuentro vital con estos chicos y chicas, que son nuestro futuro común.

En estas líneas hemos promovido una reflexión teórica desde el concepto de agencia sobre los significados de estas movilidades infantiles y adolescentes en un contexto transnacional y su performatividad en las sociedades receptoras. Apostar por otras narrativas y otros instrumentos epistemológicos y prácticos que incorporen la complejidad de los procesos humanos es una forma de luchar con el maltrato institucional y el racismo.

\section{Bibliografía}

Barbulescu, Rosana y Grugel, Jean (2016). «Unaccompanied minors, migration control and human rights at the EU's southern border: The role and limits of civil society activism», Migration Studies, 4 (2), 253272. Disponible en: <https://doi.org/10.1093/migration/mnwoo1>.

BARGACH, Amina (2006). «Los contextos de riesgo: menores migrantes "no" acompañados». En F. CheCA, Á. Arjona, y J. C. CheCA (eds.) Menores tras la frontera. Otra inmigración que aguarda (pp. 51-62). Barcelona: Icaria-Antrazyt.

EMPEZ, Nuria (2015). ¡Sólo valiente! Los menores que migran solos de Marruecos a Cataluña. Tesis doctoral. Universidad Autónoma de Barcelona. Disponible en: <https://www.tdx.cat/handle/10803/287989>.

Honwana, Alcinda y De Boeck, Filip (2005). Makers and Breakers. Children and Youth in Postcolonial Africa. Trenton y Dakar: Currey, Africa World Press y Codesria.

JimÉNEZ-Álvarez, M. G. (2011) Intrusos en la fortaleza: menores marroquíes migrantes en la frontera sur de Europa. Tesis Doctoral. Disponible en: $<$ https://repositorio.uam.es/xmlui/handle/10486/6842>. 
JiMÉNEZ-ÁLVAREZ, M. G. (2015). «Autonomous child migration in southern European border». En C. Ní Laoire y A. White (coords). Movement, Im/ Mobilities and Journeys. En Skelton, T. (editor-in-chief). Geographies of Children and Young People (Springer Singapore). Disponible en: <https:// doi.org/10.1007/978-981-4585-93-4_15-1>.

LE GALL, Josiane (2005). «Familles transnationales: bilan des recherches et nouvelles perspectives». Diversité Urbaine, 5 (1), 29-42.

LevitT, Peggy y Glick-Schiller, Nina (2008). «Conceptualizing simultaneity. A Transnational Social Field Perspective on Society». En A. Portes y J. DeWInd (eds.). Rethinking Migration. New Theoretical and Empirical Perspectives. New York: Berghahn Books.

Montesino, Norma y Jiménez-Álvarez, Mercedes G. (2015). «Child Mobility, Transnational Responses». Transnational Social Review, 6.

Ribas-Mateos, N. y Laiz, S. (2014). Movilidades Adolescentes. Elementos teóricos emergentes en la ruta entre Marruecos y Europa (pp. 161-185). Barcelona: Bellaterra.

Orellana, M. F.; Thorne, B.; Chee, A. y Lam, W. S. E. (2001). «Transnational childhoods: the participation of children in processes of family migration». Social Problems, 48 (4), 572-591.

OlwIG, K. F. (1999). «Narratives of the children left behind: home and identity in globalized Caribbean families». Journal of ethnic and Migration Studies, 25 (2), 312-334.

SUÁREZ-NAVAZ, L. (2006). «Un nuevo actor migratorio: jóvenes, rutas y ritos juveniles transnacionales». En F. CHECA et alii (eds.). Menores tras la frontera: otra migración que aguarda (pp.17-50). Barcelona: Icaria Antrazyt.

Trujillo Vega, M. ${ }^{a}$ Auxiliadora (2011). «Acogida inmediata a menores que migran sin referentes familiares. Reflexiones para la práctica profesional». En: La migración de menores no acompañados en España. Revista de Intervención Socioeducativa. Mayo agosto 2010. pp 112-136.

Trujillo VegA, M. ${ }^{a}$ Auxiliadora (2009). «Las personas menores de edad también emigran. Ausentes-invisibles-hipervisibles». En XXI Edición de los cursos de verano de la Universidad de Granada en Ceuta (pp. 100-107). Granada: Instituto de Estudios Ceutíes. 
Unicef y Consejo General de la Abogacía Española (2009). «Ni ilegales, ni invisibles. Realidad jurídica y social de los menores extranjeros en España». Disponible en: <https://www.unicef.es/publicacion/ni-ilegales-ni-invisibles-realidad-juridica-y-social-de-los-menores-extranjeros-en>.

Whitehead, Anny Hashim, Imad (2005). Children and Migration. Background Paper for DFID Migration Team. Centre on Migration, Globalisation and Poverty. Universidad de Sussex, Brighton (Reino Unido). 